Article

\title{
Development of One Pot Strategy for Hyper Production and In Vivo Evaluation of Lovastatin
}

\author{
Muhammad Azeem ${ }^{1}$, Muhammad Arshad ${ }^{2}$ (D), Saqib Mahmood ${ }^{3}$, Shazia Abrar ${ }^{4}$, \\ Ameer Fawad Zahoor ${ }^{5}$, Sadia Javed ${ }^{1, *}$, Bisma Tariq ${ }^{1}$ and Khizar Hayyat ${ }^{1}$ \\ 1 Department of Biochemistry, Government College University, Faisalabad 38000, Pakistan; \\ azeem.fgs@gmail.com (M.A.); bismatariq@yahoo.com (B.T.); khizarhayyat61@gmail.com (K.H.) \\ 2 Department of Basic Sciences, University of Veterinary \& Animal Sciences, Jhang Campus, \\ Jhang 35200, Pakistan; muhammad.arshad@uvas.edu.pk \\ 3 Department of Botany, Government College University, Faisalabad 38000, Pakistan; drsaqibj@gmail.com \\ 4 Department of Applied Chemistry, Government College University, Faisalabad 38000, Pakistan; \\ shaziaabrar@gcuf.edu.pk \\ 5 Department of Chemistry, Government College University, Faisalabad 38000, Pakistan; \\ fawad.zahoor@gmail.com \\ * Correspondence: drsadiajaved@yahoo.com; Tel.: +92-041-9203031
}

Academic Editor: Antonio Massa

Received: 26 August 2020; Accepted: 16 September 2020; Published: 24 September 2020

\begin{abstract}
The aim of this project was to improve the Aspergillus terreus strain and pretreatment of sugarcane bagasse as carrier substrate for bulk production of lovastatin, a cholesterol-lowering drug, in solid state fermentation. Sugarcane bagasse was treated with alkali $(1-3 \% \mathrm{NaOH})$ for the conversion of complex polysaccharides into simple sugars for better utilization of carrier substrate by microorganism for maximum lovastatin production. Ethidium bromide (time of exposure 30-180 min) was used to induce mutation in Aspergillus terreus and the best mutant was selected on the basis of inhibition zone appeared on petri plates. Fermented lovastatin was quantified by high-performance liquid chromatography. The fermented lovastatin, produced by parent and mutant Aspergillus terreus strain, was checked on body weight, blood glucose and serum cholesterol, ALT, AST, HDL-C, LDL-C, TG and TC levels of rats for their cholesterol lowering capacity. Our results indicate that selected strain along with $2 \% \mathrm{NaOH}$ treated sugar cane bagasse was best suitable for bulk production of lovastatin by fermentation and fermented lovastatin effectively lower the cholesterol level of rats.
\end{abstract}

Keywords: lovastatin; pretreatment; mutant; Aspergillus terreus; rats; fermentation; hyper-cholesterolemia

\section{Introduction}

Lovastatin belongs to an important class of statins and is frequently used as a cholesterol- lowering drug. Fungally-derived lovastatin is generally considered as a "safe drug". Aspergillus terreus is the most reported microorganism for the production of lovastatin [1,2]. As compared with synthetic statins lovastatin (monacolin K) is more effective for hypercholesterolemic conditions as it has lipid lowering capacity in the serum [3]. Lovastatin is structurally similar to hydroxylmethyl glutarate (HMG), a part of HMG-CoA just like mevastatin, which is used as a substrate in cholesterol biosynthesis through the mevalonic acid pathway [4]. Lovastatin has 20,000-fold more binding affinity than HMG-CoA [2]. Lovastatin is usually activated by in vivo hydrolysis of its lactone ring. This is the main biologically effective form of lovastatin and it also has antifungal property. Simvastatin can be synthesized by acetylation of fermented lovastatin while atorvastatin is totally a synthetic hydroxymethylglutaryl coenzyme A (HMG-CoA) reductase inhibitor (Figure 1a-c). 
(a)<smiles>CC[C@H](C)C(=O)O[C@H]1C[C@H](C)C=C2C=C[C@H](C)[C@H](CC[C@H](O)C[C@@H](O)CC(=O)O)[C@H]21</smiles>

(b)<smiles>CCC(C)(C)C(=O)O[C@H]1C[C@@H](C)C=C2C=C[C@H](C)[C@H](CC[C@H]3CC(O)CC(=O)O3)C21</smiles>

(c)<smiles>CC(C)c1c(C(=O)CNc2ccccc2)c(-c2ccccc2)c(-c2cccc(F)c2)n1CCC[C@@H](O)C[C@@H](O)CC(=O)O</smiles>

Figure 1. Structures of statins: (a) structure of lovastatin; (b) simvastatin; (c) atorvastatin.

The lactone ring after hydrolysis has structural similarity to the tetrahedral intermediate synthesized by reductase to bind the drug with HMG-CoA reductase [4]. The double ring of lovastatin attaches to coenzyme $\mathrm{A}$ in the active site. This process inhibits mevalonate synthesis which leads to inhibition of cholesterol production in the body (Figure 2). This causes a reduction of LDL cholesterol in serum and triglyceride, with elevation in HDL cholesterol [5]. Lovastatin has also been considered a promising compound in the treatment of the pathophysiology of fragile $\mathrm{X}$ syndrome [6]. Hyper production of various useful products by microbial culture is the main objective nowadays. Certain processes for instance, mutagenesis, selection and genetic engineering are being used for the hyper production of certain useful products by improving microbial strains [7]. A mutagenic treatment is also a useful method for high productivity of important industrial products [8].

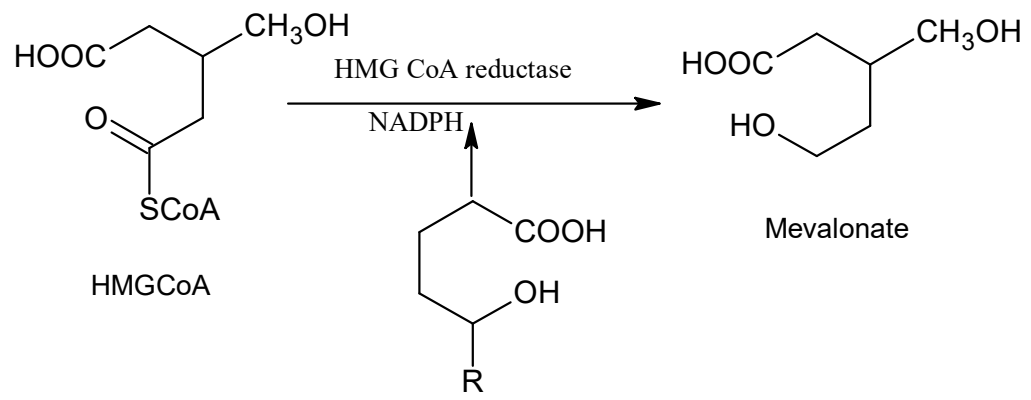

Lovastatin

Figure 2. Mechanism of action of lovastatin. 
Pretreatment of lignocellulosic biomass is a very effective way of degrading biomass into simpler molecules before enzymatic hydrolysis. There are few effective pretreatments that significantly enable cellulosic fraction of lignocellulosic biomass cell wall for enzymatic hydrolysis of cellulosic degradation into simpler monomers molecules [7,8]. Acid-base pretreatment is the most efficient method for degradation and removal of lignin and hemicellulose from sugarcane bagasse and gives high amounts of fermentable sugar on enzymatic hydrolysis [9-11]. Therefore, the present study was planned with the main objective to develop a hyper producing mutant of Aspergillus terreus and hydrolysis of complex polysaccharide of sugarcane bagasse by alkali treatment for bulk production of and comparison of both strains of Aspergillus terreus; parent and chemically improved along with synthetic atorvastatin to estimate their hypocholesterolemic efficiency in rats.

\section{Results and Discussion}

In the present study the compositional analysis of sugarcane bagasse revealed that sugarcane bagasse consists of $42 \%$ cellulose, $21.25 \%$ hemicelluloses, $22.76 \%$ lignin, $2.97 \%$ total sugars, $7.19 \%$ reducing sugars, $0.86 \%$ ash and 7.3\% moisture content. However, Javed et al., [12] found $40 \%$ cellulose, $21 \%$ hemicelluloses, $23 \%$ lignin and $0.9 \%$ ash contents in sugarcane bagasse. Moreover, Rocha et al. [13] reported $21.1 \%$ lignin, $27 \%$ hemicellulose, $45.5 \%$ cellulose and $2.2 \%$ ash in sugarcane bagasse while Rabelo et al. [14] revealed 25\% lignin, $23.2 \%$ hemicellulose, $38.4 \%$ cellulose, and 1.5\% ash in sugarcane bagasse. To facilitate the rapid and efficient hydrolysis and conversion of carbohydrates to fermentable sugars it is necessary to hydrolyze the biomass into macroscopic and microscopic size and its submicroscopic structural and chemical composition [15]. Cell wall is made up of complex polysaccharides including lignin, cellulose and hemicellulose that limit the availability of substrate due to shielding effect of these polysaccharides. Chemical and enzyme mediated pretreatments disrupt the sugarcane bagasse cell wall by degradation of the lignin, hemicellulose and cellulose. $\mathrm{NaOH}$ breaks the $\alpha$-aryl ester bonds of polyphenolic monomers and weakens the H-bonds that promote the swelling of cellulose [16].

A comparison of the Fourier transform infrared (FTIR) spectra of native and $\mathrm{NaOH}$ treated sugarcane bagasse is shown in Figure 3a-d. Figure 3a indicates the region around $1.247 \mathrm{~cm}^{-1} \mathrm{was}$ characteristic of hemicellulose and lignin due to the stretching of C-O bond [17]. A band around $1.457 \mathrm{~cm}^{-1}$ has shown a deformation of lignin $\mathrm{CH}_{2}$ and $\mathrm{CH}_{3}$, and band around $1.508 \mathrm{~cm}^{-1}$ represents the $C=C$ stretching of the aromatic ring in lignin $[18,19]$. The band around $1.636 \mathrm{~cm}^{-1}$ exhibits the stretching of the $\mathrm{C}=\mathrm{O}$ and $\mathrm{C}=\mathrm{C}$ lignin aromatic rings. A band around $1.733 \mathrm{~cm}^{-1}$ is characteristic of $\mathrm{C}=\mathrm{O}$ stretching of unconjugated hemicellulose. The region between 3.801 and $3.676 \mathrm{~cm}^{-1}$ indicates the crystalline structure of cellulose. This region constitutes the sum of the vibration of valence bands of the $\mathrm{H}$-bond of the $\mathrm{OH}$ group and the bands of intramolecular and intermolecular H-bonds [20]. Figure $3 a, b, d$ show the FTIR spectrum of $1 \%, 2 \%$ and $3 \%$ alkali-treated sugarcane bagasse, respectively. The region between 1.300 and $1.700 \mathrm{~cm}^{-1}$ clearly shows peaks after alkali hydrolysis indicating the removal of hemicellulose. In the region of $1.245 \mathrm{~cm}^{-1}$, the removal of hemicellulose is also evident.

Alkaline hydrolysis promotes removal of lignin moieties. The lignin macromolecule regions around $1.868 \mathrm{~cm}^{-1}, 1.733 \mathrm{~cm}^{-1}$, and $1.580 \mathrm{~cm}^{-1}$ and cellulose-containing regions around $2.918 \mathrm{~cm}^{-1}$ and $2.850 \mathrm{~cm}^{-1}$ have shown noticeable changes after alkaline hydrolysis. It is evident from these changes that a delignification process has occurred in the sugarcane bagasse.

From ethidium bromide (EB) treated plates, 10 hyperproducing mutants were selected on the basis of their efficiency on plates. A total of 10 positive mutants were picked predominantly on the basis of their bigger zone of inhibition on Candida albicans grown on agar plates (Figure 4). The mutant ATE-120 obtained at $120 \mathrm{~min}$ dose of EB manifested $44 \mathrm{~mm}$ clearance zone (Figure 4 ). 

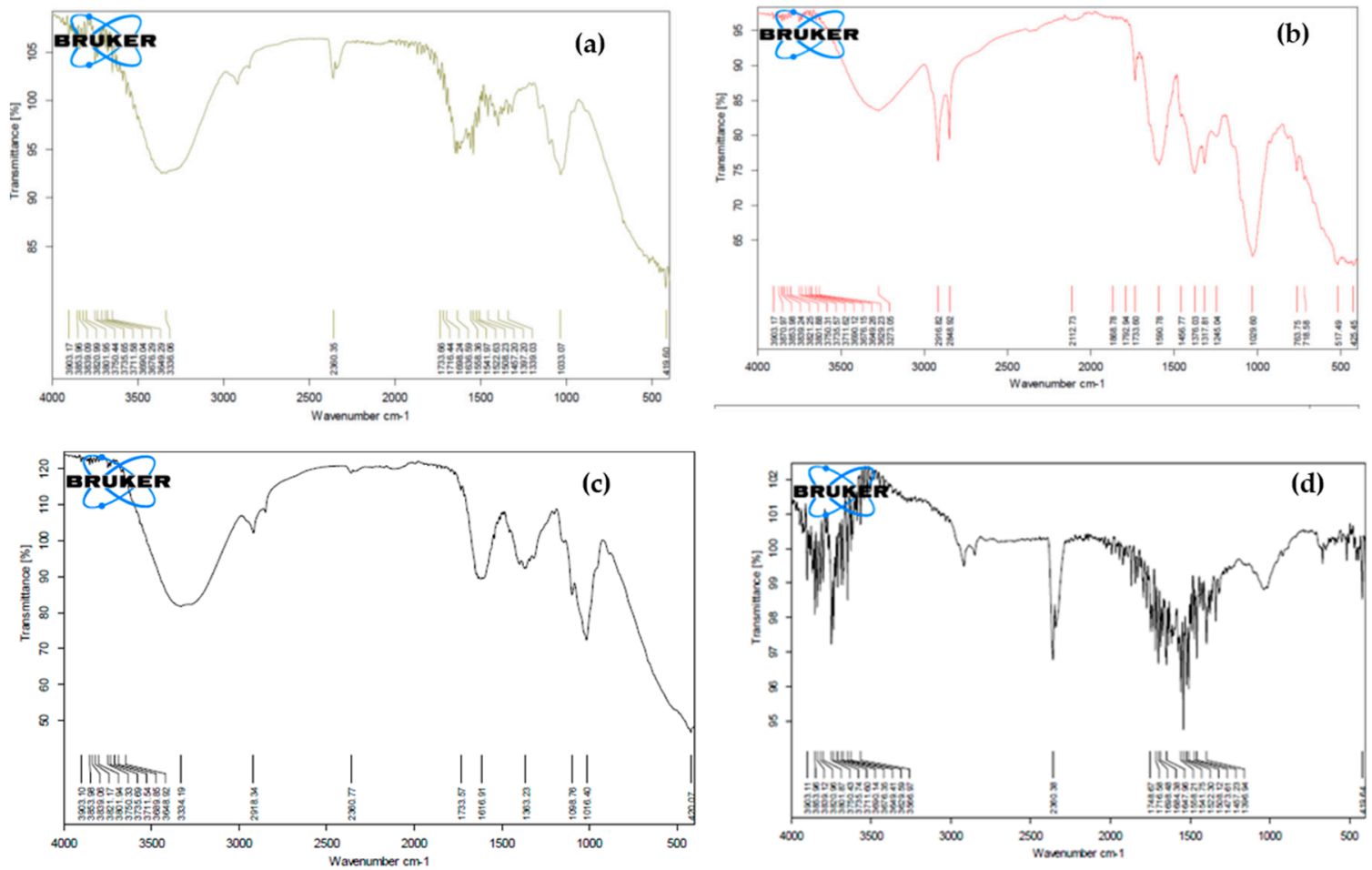

Figure 3. Fourier Transform Infrared Spectroscopy (FTIR) for bagasse (a) native (b) treated with $1 \%$ $\mathrm{NaOH}($ c) $2 \% \mathrm{NaOH}$ (d) $3 \% \mathrm{NaOH}$.

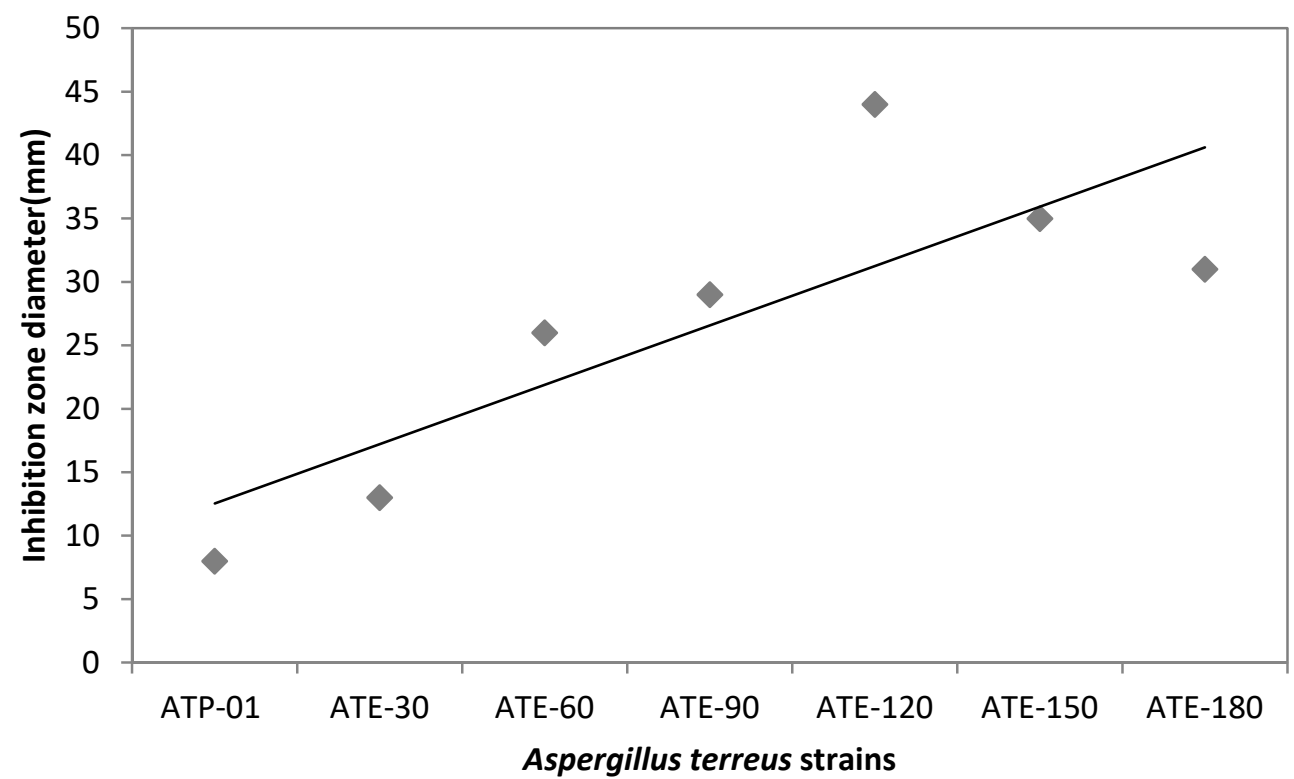

Figure 4. Inhibition zone diameter on plate vs. Aspergillus terreus parent and mutant strains. ATP-01: Aspergillus terreus parent strain; ATE: Aspergillus terreus treated with ethidium bromide with various time of exposures (30-180 $\mathrm{min}$ ).

These mutants were also evaluated through still culture flask experiments. The mutants of Aspergillus terreus along with parent strain were used for production, using sugarcane bagasse in solid state fermentation (SSF). Among these, the maximum production $(91 \pm 1.77 \mathrm{mg} / \mathrm{L})$ with dry cell mass $(4.49 \pm 0.81 \mathrm{~g} / \mathrm{L})$ was noticed for the mutant ATE-120 using $2 \% \mathrm{NaOH}$ treated sugarcane bagasse (Table 1). The results indicated that ATE-120 was the most hyper-active mutant, producing more lovastatin over the parent strain $(23 \pm 1.54 \mathrm{mg} / \mathrm{L})$ in similar culture conditions. Ferron et al. [21] reported 
a positive correlation between the lovastatin titer obtained in liquid cultures of the isolate and the measured diameter of inhibition zone on agar which is in accordance with our work. Samiee et al. [22] also noticed that Aspergillus terreus is a best lovastatin $(55 \mathrm{mg} / \mathrm{L})$ producing strain out of 110 fungal strains. Mangunwardoyo et al. [23] detected the highest lovastatin production (85.88 $\mathrm{mg} / \mathrm{L})$ by Aspergillus flavus UICC 360. Moreover, Lakshman and Radha [2] find out a maximum lovastatin concentration $(113 \mu \mathrm{g} / \mathrm{mL})$ by P. ostreatus.

Table 1. Production of lovastatin by various strains growing over native and treated substrates.

\begin{tabular}{|c|c|c|c|c|c|c|c|c|}
\hline \multirow[b]{2}{*}{ Strains } & \multicolumn{2}{|c|}{ Native } & \multicolumn{2}{|c|}{$1 \% \mathrm{NaOH}$} & \multicolumn{2}{|c|}{$2 \% \mathrm{NaOH}$} & \multicolumn{2}{|c|}{$3 \% \mathrm{NaOH}$} \\
\hline & $\begin{array}{c}\text { Lovastatin } \\
(\mathrm{mg} / \mathrm{L})\end{array}$ & $\begin{array}{c}\text { Biomass } \\
\text { (g) }\end{array}$ & $\begin{array}{l}\text { Lovastatin } \\
(\mathrm{mg} / \mathrm{L})\end{array}$ & $\begin{array}{c}\text { Biomass } \\
\text { (g) }\end{array}$ & $\begin{array}{l}\text { Lovastatin } \\
(\mathrm{mg} / \mathrm{L})\end{array}$ & $\begin{array}{c}\text { Biomass } \\
\text { (g) }\end{array}$ & $\begin{array}{c}\text { Lovastatin } \\
(\mathrm{mg} / \mathrm{L})\end{array}$ & $\begin{array}{c}\text { Biomass } \\
(\mathrm{mg} / \mathrm{L})\end{array}$ \\
\hline Parent & $8.35 \pm 0.56$ & $4.16 \pm 0.11$ & $18.31 \pm 0.96$ & $3.28 \pm 0.11$ & $20.28 \pm 0.69$ & $3.81 \pm 0.67$ & $34.54 \pm 0.61$ & $4.22 \pm 0.59$ \\
\hline ATE-30 & $11.28 \pm 0.56$ & $4.28 \pm 0.11$ & $33.43 \pm 1.17$ & $3.28 \pm 0.14$ & $34.17 \pm 0.33$ & $3.27 \pm 0.17$ & $37.16 \pm 1.11$ & $4.33 \pm 0.23$ \\
\hline ATE-60 & $15.72 \pm 5.15$ & $3.66 \pm 0.21$ & $21.33 \pm 1.01$ & $4.21 \pm 0.33$ & $46.33 \pm 0.56$ & $4.31 \pm 0.41$ & $39.11 \pm 1.34$ & $3.58 \pm 0.27$ \\
\hline ATE-90 & $11.67 \pm 1.01$ & $4.67 \pm 0.33$ & $48.51 \pm 1.22$ & $4.61 \pm 0.51$ & $51.37 \pm 0.81$ & $4.56 \pm 0.61$ & $45.65 \pm 1.30$ & $4.13 \pm 0.32$ \\
\hline ATE-120 & $16.32 \pm 0.97$ & $3.84 \pm 0.55$ & $52.14 \pm 1.31$ & $4.88 \pm 0.41$ & $91 \pm 1.77$ & $4.49 \pm 0.27$ & 51.12. \pm 1.61 & $4.66 \pm 0.31$ \\
\hline ATE-150 & $12.31 \pm 1.21$ & $3.54 \pm 0.43$ & $44.45 \pm 1.12$ & $3.91 \pm 0.31$ & $74.76 \pm 1.22$ & $3.64 \pm 0.34$ & $53.31 \pm 1.51$ & $4.31 \pm 0.25$ \\
\hline ATE-180 & $13.32 \pm 0.79$ & $4.20 \pm 0.34$ & $39.18 \pm 0.97$ & $3.87 \pm 0.51$ & $64.10 \pm 1.22$ & $4.12 \pm 0.53$ & $49.28 \pm 1.32$ & $4.56 \pm 0.35$ \\
\hline
\end{tabular}

Besides, the blood glucose levels of high cholesterol dietfor fermented parent derived lovastatin (PL), mutant derived lovastatin (ML), and atorvastatin groups were crucially higher than in control group during the whole experimental period after administration of high cholesterol diet in rats (Table 2). Concentrations of serum cholesterol in rats fed on high cholesterol diet rats were slightly higher than those in normal control rats. It was also observed that cholesterol level was notably lower in rats treated with parent, mutant derived lovastatin and atorvastatin than in high cholesterol diet (HCD) group at 20 and 60 days. Changes in body and kidney weights in the five groups of rats are shown in Table 1. Moreover, the reactive oxygen species (ROS), developed in response to increase in blood glucose and lipid levels, are the main causative agents for liver damage [24].

Table 2. Effect of fermented lovastatin on body weight, blood glucose and serum cholesterol levels in rats.

\begin{tabular}{ccccc}
\hline Groups & Days & Body Weight $(\mathbf{g})$ & Blood Glucose Level (mg/dL) & Serum Cholesterol Level (mg/dL) \\
\hline \multirow{4}{*}{ Control } & 20 & $230 \pm 10$ & $160 \pm 12$ & $63 \pm 5$ \\
& 40 & $265 \pm 13$ & $186 \pm 11$ & $61 \pm 3$ \\
& 60 & $281 \pm 14$ & $180 \pm 15$ & $58 \pm 5$ \\
HCD & 40 & $221 \pm 11$ & $470 \pm 12$ & $70 \pm 4$ \\
& 60 & $245 \pm 15$ & $510 \pm 13$ & $63 \pm 6$ \\
& 20 & $215 \pm 15$ & $540 \pm 11$ & $65 \pm 10$ \\
HCD-PL & 40 & $232 \pm 10$ & $430 \pm 10$ & $61 \pm 3$ \\
& 60 & $250 \pm 13$ & $390 \pm 9$ & $68 \pm 4$ \\
HCD-ML & 40 & $235 \pm 13$ & $425 \pm 14$ & $55 \pm 5$ \\
& 60 & $250 \pm 16$ & $410 \pm 15$ & $62 \pm 3$ \\
& 20 & $220 \pm 17$ & $360 \pm 13$ & $58 \pm 5$ \\
HCD-SA & 40 & $231 \pm 12$ & $350 \pm 11$ & $65 \pm 7$ \\
& 60 & $234 \pm 14$ & $445 \pm 14$ & $67 \pm 4$ \\
\hline
\end{tabular}

Values (Mean \pm SD) are average of six samples, Analyzed individually in triplicate $(\mathrm{n}=1 \times 3 \times 3) p \leq 0.05$. HCD: High Cholesterol diet. HCD-PL: High cholesterol diet and parent strain derived lovastatin. HCD-ML: High Cholesterol diet and mutant strain derived lovastatin. HCD-SS: High cholesterol diet and synthetic atorvastatin.

The findings of the present study also demonstrated that the serum aspartate aminotransferase (AST) and alanine aminotransferase (ALT) were remarkably increased in high cholesterol diet (HCD) than normal and fermented lovastatin (PL \& ML) diet. Serum total cholesterol (TC), triglycerides (TG) and low density lipoproteins (LDL) levels were also notably increased after 20, 40 and 60 days. Thus, HDL-cholesterol level reduced in high cholesterol diet (HCD) group as compared to normal 
rats. These findings are in close agreement with the Stepherd [25] work who found the inhibition of HMG-CoA reductase by a class of drug statins in rat liver. The reason behind increase in LDL-cholesterol concentration might be the reduction in receptors or reduced low density lipoproteins (LDL) binding to its receptor [26]. This change in receptor is responsible for the elevation of blood cholesterol level, in response to high cholesterol diet (HCD). In the present study, fermented lovastatin (PL and ML) and synthetic atorvastatin reduced the total cholesterol (TC), triglycerides (TG) and low density lipoproteins (LDL) levels and increased the high dentistry lipoproteins (HDL) level (Table 3). Low level of high density lipoproteins (HDL) may develop atherosclerosis because high density lipoproteins (HDL) absorb cholesterol and transport it to the liver for metabolism. In hypocholesterolemic rats, decreased HDL level may be due to reduced activity of lipoprotein lipase (LPL). LPL is a water-soluble enzyme that catalyzes the hydrolysis of triglycerides (TGs) into lipoproteins. A decrease in lipoprotein lipase activity is associated with an increase and decrease in high density lipoprotein (HDL) and plasma triglycerides (TGs) respectively.

Table 3. Effect of fermented lovastatin on lipid profile in rats.

\begin{tabular}{|c|c|c|c|c|c|c|c|c|}
\hline Groups & Days & $\begin{array}{c}\text { AST } \\
(\mathrm{mmol} / \mathrm{L})\end{array}$ & $\begin{array}{c}\text { ALT } \\
(\mathrm{mmol} / \mathrm{L})\end{array}$ & $\begin{array}{c}\text { HDL-C } \\
\text { (mmol/L) }\end{array}$ & $\begin{array}{c}\text { LDL-C } \\
\text { (mmol/L) }\end{array}$ & $\begin{array}{c}\text { TG } \\
(\mathrm{mmol} / \mathrm{L})\end{array}$ & $\begin{array}{c}\text { TC } \\
(\mathrm{mmol} / \mathrm{L})\end{array}$ & $\% \mathrm{TC} / \mathrm{HDL}-\mathrm{C}$ \\
\hline \multirow{4}{*}{ Control } & 20 & $188 \pm 8.44$ & $62 \pm 4.44$ & $0.71 \pm 0.03$ & $0.50 \pm 0.02$ & $1.3 \pm 0.01$ & $1.82 \pm 0.04$ & 2.5 \\
\hline & 40 & $182 \pm 10.11$ & $60 \pm 3.11$ & $0.78 \pm 0.05$ & $0.48 \pm 0.03$ & $1.24 \pm 0.03$ & $1.75 \pm 0.03$ & 2.2 \\
\hline & 60 & $183 \pm 7.90$ & $61 \pm 8.16$ & $0.75 \pm 0.09$ & $0.50 \pm 0.05$ & $1.4 \pm 0.04$ & $1.8 \pm 0.00$ & 2.4 \\
\hline & 20 & $240 \pm 11.21$ & $58 \pm 7.32$ & $0.38 \pm 0.04$ & $7.45 \pm 0.91$ & $1.5 \pm 0.02$ & $7.3 \pm 0.12$ & 19.2 \\
\hline \multirow[t]{3}{*}{ HCD } & 40 & $236 \pm 9.38$ & $57 \pm 5.87$ & $0.36 \pm 0.01$ & $7.98 \pm 0.24$ & $1.57 \pm 0.05$ & $6.88 \pm 0.08$ & 19.1 \\
\hline & 60 & $235 \pm 8.47$ & $59 \pm 5.44$ & $0.35 \pm 0.03$ & $8.84 \pm 0.17$ & $1.6 \pm 0.06$ & $6.2 \pm 0.14$ & 17.7 \\
\hline & 20 & $209 \pm 10.11$ & $61 \pm 6.10$ & $0.50 \pm 0.01$ & $6.54 \pm 0.65$ & $1.75 \pm 0.04$ & $4.2 \pm 0.11$ & 8.4 \\
\hline \multirow[t]{3}{*}{ HCD-PL } & 40 & $203 \pm 6.38$ & $62 \pm 6.88$ & $0.51 \pm 0.05$ & $5.63 \pm 0.41$ & $1.6 \pm 0.05$ & $4.8 \pm 0.08$ & 9.4 \\
\hline & 60 & $204 \pm 9.19$ & $59 \pm 6.54$ & $0.53 \pm 0.09$ & $5.87 \pm 0.33$ & $1.7 \pm 0.04$ & $4.5 \pm 0.09$ & 8.5 \\
\hline & 20 & $195 \pm 11.32$ & $64 \pm 6.21$ & $0.61 \pm 0.07$ & $4.32 \pm 0.90$ & $1.77 \pm 0.08$ & $3.45 \pm 0.07$ & 5.6 \\
\hline \multirow[t]{3}{*}{ HCD-ML } & 40 & $190 \pm 9.67$ & $65 \pm 8.44$ & $0.62 \pm 0.06$ & $4.18 \pm 0.46$ & $1.8 \pm 0.06$ & $3.1 \pm 0.01$ & 5 \\
\hline & 60 & $191 \pm 12.21$ & $64 \pm 6.11$ & $0.65 \pm 0.05$ & $3.87 \pm 0.16$ & $1.64 \pm 0.01$ & $3.87 \pm 0.12$ & 5.9 \\
\hline & 20 & $208 \pm 12.80$ & $53 \pm 5.19$ & $0.50 \pm 0.02$ & $6.81 \pm 0.80$ & $0.9 \pm 0.06$ & $5.4 \pm 0.90$ & 10.8 \\
\hline \multirow[t]{2}{*}{ HCD-SS } & 40 & $206 \pm 9.73$ & $55 \pm 2.08$ & $0.49 \pm 0.07$ & $6.13 \pm 0.73$ & $0.8 \pm 0.07$ & $5.2 \pm 0.13$ & 10.6 \\
\hline & 60 & $207 \pm 11.61$ & $51 \pm 4.17$ & $0.47 \pm 0.05$ & $5.81 \pm 0.65$ & $1.1 \pm 0.05$ & $5 \pm 0.15$ & 10.6 \\
\hline
\end{tabular}

Values (Mean \pm SD) are average of six samples, Analyzed individually in triplicate $(\mathrm{n}=1 \times 3 \times 3) p \leq 0.05$. HCD: High Cholesterol diet. HCD-PL: High cholesterol diet and parent strain derived lovastatin. HCD-ML: High Cholesterol diet and mutant strain derived lovastatin. HCD-SS: High cholesterol diet and synthetic atorvastatin. Aspartate aminotransferase (AST). Alanine aminotransferase (ALT). High density lipoproteins cholesterol (HDL-C). Low density lipoproteins cholesterol (LDL-C). Triglycerides (TC). Total cholesterol (TC).

\section{Material and Methods}

\subsection{Pretreatment of Substrate}

Sugarcane bagasse was obtained from Shakarganj Sugars Mills Jhang (Jhang, Pakistan. The sugarcane bagasse was washed thoroughly with cold water to remove dust and was ground to $40 \mathrm{~mm}$. Thirty $\mathrm{mL}$ samples of $\mathrm{NaOH}$ with different concentrations (1-3\%) were made and $2 \mathrm{~g}$ of powdered bagasse was added to each concentration. These samples were kept at $80^{\circ} \mathrm{C}$ and neutral $\mathrm{pH}$ in microwave for 10 min then filtered and rinsed with tap water. The pretreated samples were dried at $65^{\circ} \mathrm{C}$ [9]. The native and treated sugarcane bagasse samples were analyzed using Fourier Transform Infrared Spectroscopy (FTIR) by the method of Chandel et al., [11]. The spectra were collected in the range 4000 to $500 \mathrm{~cm}^{-1}$ with a resolution of $4 \mathrm{~cm}^{-1}$ per minute and room temperature detector (Tensor II FTIR, Bruker, Bremen, Germany).

\subsection{Mutagenic Treatments}

Ethidium bromide was used to induce mutation in the Aspergillus terreus strain. A stock solution of $0.5 \mathrm{mg} / \mathrm{mL}$ ethidium bromide $(w / v)$ was prepared. The stock solution of EB (Sigma-Aldrich, Gillingham, UK) was prepared. It was mixed with Vogel medium $(9 \mathrm{~mL})$, which contained $1 \times 107$ spores $\mathrm{mL}^{-1}$ of Aspergillus terreus and kept it in a water bath (Eyela, Tokyo, Japan) at $37^{\circ} \mathrm{C}$. One milliliter sample was withdrawn after a specific time interval, and cell pellet was washed thrice with normal saline solution. 
The sample was centrifuged at 12,000 rpm for $1 \mathrm{~min}$ using centrifuge machine (Mikro 20 Hettich, Tuttlingen, Germany), to separate out the mutagen from sample [9].

\subsection{Selection of Best Mutant}

Candida albicans was used for the selection of best mutant. It was grown on PDA dishes at $28^{\circ} \mathrm{C}$ for $12 \mathrm{~h} .50 \mu \mathrm{L}$ of fermented lovastatin extract were added onto a $6 \mathrm{~mm}$ diameter paper disk. These paper disks were placed on the surface of a $90 \mathrm{~mm}$ diameter $C$. albicans plate. The maximum distance of $15 \mathrm{~mm}$ was kept between lovastatin impregnated disks on a plate. The plates were incubated for $6 \mathrm{~h}$ and zones of inhibition were recorded. A large diameter of the inhibition zone implied a high titer of lovastatin [21].

\subsection{Lovastatin Production}

Lovastatin was produced in solid state fermentation (SSF) by the method as described by Javed et al. [9]. Experiments were performed using $500 \mathrm{~mL}$ Erlenmeyer flasks in a temperature-controlled incubator (SLI-600ND, Eyela). Two g of sugar cane bagasse as a carrier substrate was taken in triplicate $500 \mathrm{~mL}$ Erlenmeyer flasks moistened with $7 \mathrm{~mL}$ Vogel medium. $\mathrm{pH}$ was adjusted to 6 using $\mathrm{M} \mathrm{NaOH} / \mathrm{M}$ $\mathrm{HCl}$ solutions and SSF media flasks were sterilized $\left(121^{\circ} \mathrm{C}\right)$ in autoclave for $15 \mathrm{~min}$. After cooling to room temperature, the triplicate flasks were inoculated with $5 \mathrm{~mL}$ of homogenous spore suspension of Aspergillus terreus and the flasks were subjected to SSF under still culture conditions for $72 \mathrm{~h}$.

\subsection{Extraction of Lovastatin}

$10 \% 1 \mathrm{~N} \mathrm{HCl}$ was added to the fermentation broth after 3 days of fermentation. The acidified broth was extracted with equal volume of ethyl acetate at $70{ }^{\circ} \mathrm{C}$ temperature and $180 \mathrm{rpm}$ for $2 \mathrm{~h}$. The Whatman filter paper No. 40 was used for the filtration of broth. The filtrate was centrifuged at $3000 \mathrm{rpm}$ for ten mins and the organic phase was collected. $10 \mathrm{~mL}$ of $1 \%$ trifluoroacetic acid was mixed in the one $\mathrm{ml}$ of organic phase of filtrate for lactonization. The extract was heated at $80^{\circ} \mathrm{C}$ to evaporate the moisture, diluted with one $\mathrm{mL}$ acetonitrile and filtered for high-HPLC analysis.

\subsection{Analysis of Lovastatin}

The identification and quantification of lovastatin was carried out by HPLC method [27]. The samples were prepared by 10 fold diluting the filtered broth with acetonitrile-water (1:1 by volume) and analyzed using an HPLC (Hitachi, Ibaraki, Japan) equipped with a UV detector (Hitachi L-2400) at $238 \mathrm{~nm}$ and a Hitachi L-2130 (C-18) column. The solvent was prepared by mixing acetonitrile and $0.1 \%$ phosphoric acid (60:40 by volume). A $20 \mu \mathrm{L}$ sample was injected with a flow rate of $1.5 \mathrm{~mL} \mathrm{~min}^{-1}$.

\subsection{In Vivo Application of Lovastatin}

Thirty male albino rats were selected for the induction of lovastatin. These male rats of 200-230 g of weight were obtained from National Institute of Health (Islamabad, Pakistan). These albino rats were group into 5 groups each containing 6 rats and caged into separate cages under suitable temperature of $25 \pm 5{ }^{\circ} \mathrm{C}$. Proper ventilation system is maintained and standard feed and tap water is provided according to their weight. According to the method explained by Kamal and Thanaa [26] with high cholesterol diet was prepared. $20 \mathrm{mg}$ /day lovastatin dose was administered to rats, fed on high cholesterol diet. Five groups were made according to their diet:

Group 1 contains normal rats on normal diet

Group 2 contains rats with high cholesterol diet (HCD)

Group $3 \mathrm{HCD}+$ fermented lovastatin derived from parent Aspergillus terreus strain (PL)

Group $4 \mathrm{HCD}+$ fermented lovastatin derived from mutant Aspergillus terreus strain (ML)

Group 5 contains rats which are on synthetic statin 
The efficacy of fermented lovastatin on serum of rats AST, HDL-C, ALT, LDL-C, TC and TG level of rats was determined by the method of Kamal and Thanaa, [26] and Javed et al. [9]. Concentration of serum cholesterol was determined by a Cholesterol-E kit. Blood glucose level was determined by a standard kit method.

\subsection{Statistical Analysis}

Statistical significance of the differences between mean values was calculated by ANOVA under CRD and DMR test using Minitab 2000 version 13.2 statistical software (Minitab Inc., State College, PA, USA). A probability value of $p \leq 0.05$ was considered to denote a statistically significant difference [28].

\section{Conclusions}

It can be inferred from the present study that strain improvement of Aspergillus terreus using ethidium bromide and pretreatment of sugarcane bagasse using $\mathrm{NaOH}$ for hydrolysis of complex polysaccharides for better utilization of substrate by fungal strain were effective strategies to hyperproduce lovastatin and successfully treat hypercholesterolemia. The present data would certainly help to ascertain the ability of fermented lovastatin as the potential drug for hypercholesterolemia to be used in the pharmaceutical industry.

Author Contributions: M.A. (Muhammad Azeem); Investigation, formal analysis, M.A. (Muhammad Arshad); Resources S.M.; Resources, S.A.; conceptualization A.F.Z.; Resources, S.J.; Supervision, conceptualization, writing-review, methodology, Resources, B.T.; Formal analysis, K.H.; Methodology, writing. All authors have read and agreed to the published version of the manuscript.

Funding: This research received no external funding.

Acknowledgments: Authors are thankful to Sajjad-ur-Rehman, Institute of Microbiology, University of Agriculture, Faisalabad, Pakistan for providing the parent Aspergillus terreus strain.

Conflicts of Interest: The authors declare no conflict of interests.

\section{References}

1. Seenivasan, A.; Sankar, P.; Gummadi, S.N.; Panda, T.; Ch, V.; Eswari, J.S.; Venkateswarlu, C. Metabolic pathway analysis and dynamic macroscopic model development for lovastatin production by Monascus purpureus using metabolic footprinting concept. Biochem. Eng. J. 2020, 154, 107437. [CrossRef]

2. Lakshmanan, D.; Radha, K. An effective quantitative estimation of lovastatin from Pleurotus ostreatus using UV and HPLC. Int. J. Pharm. Pharm. Sci. 2012, 4, 462-464.

3. Zhang, Y.; Chen, Z.; Wen, Q.; Xiong, Z.; Cao, X.; Zheng, Z.; Zhang, Y.; Huang, Z. An overview on the biosynthesis and metabolic regulation of monacolin K/lovastatin. Food Funct. 2020. [CrossRef]

4. Stancu, C.; Sima, A. Statins: Mechanism of action and effects. J. Cell. Mol. Med. 2007, 5, 378-387. [CrossRef]

5. Groll, M.; Huber, R.; Potts, B.C.M. Crystal Structures of Salinosporamide A (NPI-0052) and B (NPI-0047) in Complex with the 20S Proteasome Reveal Important Consequences of $\beta$-Lactone Ring Opening and a Mechanism for Irreversible Binding. J. Am. Chem. Soc. 2006, 128, 5136-5141. [CrossRef] [PubMed]

6. Thurman, A.J.; Potter, L.A.; Kim, K.; Tassone, F.; Banasik, A.; Potter, S.N.; Bullard, L.; Nguyen, V.; McDuffie, A.; Hagerman, R.; et al. Controlled trial of lovastatin combined with an open-label treatment of a parent-implemented language intervention in youth with fragile X syndrome. J. Neurodev. Disord. 2020, 12, 1-17. [CrossRef] [PubMed]

7. Namazi, M.R. Statins: Novel additions to the dermatologic arsenal? Exp. Dermatol. 2004, 13, 337-339. [CrossRef] [PubMed]

8. Parekh, S.; Vinci, V.A.; Strobel, R.J. Improvement of microbial strains and fermentation processes. Appl. Microbiol. Biotechnol. 2000, 54, 287-301. [CrossRef]

9. Awan, M.S.; Tabbasam, N.; Ayub, N.; Babar, M.E.; Rahman, M.-U.; Rana, S.M.; Rajoka, M.I. Gamma radiation induced mutagenesis in Aspergillus niger to enhance its microbial fermentation activity for industrial enzyme production. Mol. Biol. Rep. 2010, 38, 1367-1374. [CrossRef] 
10. Javed, S.; Bukhari, S.; Zovia, I.; Meraj, M. Screening of Indigenously Isolated Fungi for Lovastatin Production and Its in vivo Evaluation. Curr. Pharm. Biotechnol. 2014, 15, 422-427. [CrossRef]

11. Chandel, A.K.; Antunes, F.A.; Anjos, V.; Bell, M.J.V.; Rodrigues, L.N.; Polikarpov, I.; De Azevedo, E.R.; Bernardinelli, O.D.; Rosa, C.A.; Pagnocca, F.C.; et al. Multi-scale structural and chemical analysis of sugarcane bagasse in the process of sequential acid-base pretreatment and ethanol production by Scheffersomyces shehatae and Saccharomyces cerevisiae. Biotechnol. Biofuels 2014, 7, 63. [CrossRef] [PubMed]

12. Javed, S.; Bukhari, S.A.; Ali, M.; Rehman, S.-U. Estimation of Antifungal Activity of Mevastatin Produced by Aspergillus terreus GCBL-03 on pretreated substrate in solid state fermentation. Curr. Pharm. Biotechnol. 2016, 17, 291-298. [CrossRef] [PubMed]

13. Rocha, G.J.D.M.; Martin, C.; Soares, I.B.; Maior, A.M.S.; Baudel, H.M.; De Abreu, C.A.M. Dilute mixed-acid pretreatment of sugarcane bagasse for ethanol production. Biomass Bioenergy 2011, 35, 663-670. [CrossRef]

14. Rabelo, S.; Carrere, H.; Filho, R.M.; Da Costa, A.C. Production of bioethanol, methane and heat from sugarcane bagasse in a biorefinery concept. Bioresour. Technol. 2011, 102, 7887-7895. [CrossRef] [PubMed]

15. Chang, V.S.; Holtzapple, M.T. Fundamental factors affecting enzymatic reactivity. App. Biochem. Biotechnol. 2000, 84, 5-37. [CrossRef]

16. Ko, J.K.; Bak, J.S.; Jung, M.W.; Lee, H.J.; Choi, I.-G.; Kim, T.H.; Kim, K.H.; Jung, Y.H. Ethanol production from rice straw using optimized aqueous-ammonia soaking pretreatment and simultaneous saccharification and fermentation processes. Bioresour. Technol. 2009, 100, 4374-4380. [CrossRef] [PubMed]

17. Pandey, K.; Pitman, A. FTIR studies of the changes in wood chemistry following decay by brown-rot and white-rot fungi. Int. Biodeterior. Biodegrad. 2003, 52, 151-160. [CrossRef]

18. Fajula, X.C.; Carrillo, F.; Nogués, F.; Garriga, P. Structural analysis of photodegraded wood by means of FTIR spectroscopy. Polym. Degrad. Stab. 2003, 80, 543-549. [CrossRef]

19. Pandey, K.K. Study of the effect of photo-irradiation on the surface chemistry of wood. Polym. Degrad. Stab. 2005, 90, 9-20. [CrossRef]

20. Hinterstoisser, B.; Salmén, L. Two-Dimensional step-scan FTIR: A tool to unravel the OH-valency-range of the spectrum of Cellulose I. Cellulose 1999, 6, 251-263. [CrossRef]

21. Chisti, Y.; Ferrón, M.A.V.; López, J.C.; Pérez, J.S.; Fernández-Sevilla, J.M. Rapid screening of Aspergillus terreus mutants for overproduction of lovastatin. World J. Microbiol. Biotechnol. 2005, 21, 123-125. [CrossRef]

22. Samiee, S.M.; Moazami, N.; Haghighi, S.; Mohseni, F.A.; Mirdamadi, S.; Bakhtiari, M.A. Screening of lovastatin production by filamentous fungi. Iran. Biomed. J. 2003, 7, 29-33.

23. Mangunwardoyo, W.; Rafliyanti, Y.; Kusmana, D. Bioprospect of lovastatin in Aspergillus spp. from University of Indonesia Culture Collection (UICC). World Appl. Sci. J. 2012, 16, 183-188.

24. Hamden, K.; Jaouadi, B.; Carreau, S.; Bejar, S.; Elfeki, A. Inhibitory effect of fenugreek galactomannan on digestive enzymes related to diabetes, hyperlipidemia, and liver-kidney dysfunctions. Biotechnol. Bioprocess Eng. 2010, 15, 407-413. [CrossRef]

25. Shepherd, J. Lipids in health and disease. Biochem. Soc. Trans. 2004, 32, 1051-1056. [CrossRef]

26. Kamal, A.A.; Thanaa, M.A. Oxidative markers, nitric oxide and Homocysteine alteration in hypocholesterolemic rats: Role of atorvastatin and cinnamon. Int. J. Clin. Exp. Med. 2009, 2, 254-265.

27. López, J.C.; Pérez, J.S.; Fernández-Sevilla, J.M.; Fernández, F.G.A.; Grima, E.M.; Chisti, Y. Production of lovastatin by Aspergillus terreus: Effects of the $\mathrm{C}: \mathrm{N}$ ratio and the principal nutrients on growth and metabolite production. Enzym. Microb. Technol. 2003, 33, 270-277. [CrossRef]

28. Steel, R.G.D. Principles and Procedure of Statistics. In A Biomaterial Approach, 3rd ed.; McGraw Hill: New York, NY, USA, 1997.

Sample Availability: Samples of the compounds mutant Aspergillus terreus strain, fermented lovastatin and all chemicals used in this study are available from the authors.

(C) 2020 by the authors. Licensee MDPI, Basel, Switzerland. This article is an open access article distributed under the terms and conditions of the Creative Commons Attribution (CC BY) license (http://creativecommons.org/licenses/by/4.0/). 